\author{
Alessandra Frigerio \\ Paola Rucci \\ Robert Goodman \\ Massimo Ammaniti \\ Ombretta Carlet \\ Pina Cavolina \\ Giovanni De Girolamo \\ Carlo Lenti \\ Loredana Lucarelli \\ Elisa Mani \\ Andrea Martinuzzi \\ Nadia Micali \\ Annarita Milone \\ Pierluigi Morosini \\ Filippo Muratori \\ Franco Nardocci \\ Valentina Pastore \\ Gabriella Polidori \\ Andrea Tullini \\ Laura Vanzin \\ Laura Villa \\ Mauro Walder \\ Alessandro Zuddas \\ Massimo Molteni
}

Received: 14 December 2007

Accepted: 4 August 2008

Published online: 22 January 2009

Dr. A. Frigerio, $\mathrm{PhD}(\bowtie) \cdot$ E. Mani, MD

V. Pastore, MSc $\cdot$ L. Vanzin, MSc

L. Villa, MD - M. Molteni, MD

Scientific Institute 'E. Medea'

Via Don Luigi Monza, 20

23842 Bosisio Parini (LC), Italy

Tel.: +39-031/877111

Fax: +39-031/877499

E-Mail: alessandra.frigerio@bp.lnf.it

P. Rucci, DStat

DPNFB

University of Pisa

Pisa, Italy

P. Rucci, DStat

Western Psychiatric Institute and Clinic

University of Pittsburgh

Pittsburgh (PA), USA

R. Goodman, MD · N. Micali, MD

King's College

Institute of Psychiatry

London, UK

M. Ammaniti, MD · L. Lucarelli, MSc

Dipartimento di Psicologia Dinamica e

Clinica

University La Sapienza

Rome, Italy

\title{
Prevalence and correlates of mental disorders among adolescents in Italy: the PrISMA study
}

Abstract Background While in the last 5 years several studies have been conducted in Italy on the prevalence of mental disorders in adults, to date no epidemiological study has been targeted on mental disorders in adolescents. Method A two-phase study was conducted on 3,418 participants using the child behavior checklist/ 6-18 (CBCL) and the development and well-being assessment

O. Carlet, MD - A. Martinuzzi, MD Scientific Institute 'E. Medea' Conegliano (TV), Italy

P. Cavolina, MSc $\cdot$ A. Zuddas, MD Department of Neuroscience University of Cagliari Cagliari, Italy

G. De Girolamo, MD Department of Mental Health Azienda USL

Bologna, Italy

C. Lenti, MD · M. Walder, MD University of Milan Milan, Italy
(DAWBA), a structured interview with verbatim reports reviewed by clinicians. Results The prevalence of CBCL caseness and DSM-IV disorders was 9.8\% (CI 8.8-10.8\%) and $8.2 \%$ (CI $4.2-12.3 \%$ ), respectively. DSM-IV Emotional disorders were more frequently observed (6.5\% CI 2.2-10.8\%) than externalizing disorders $(1.2 \%$ CI $0.2-2.3 \%)$. In girls, prevalence estimates increased significantly with age; furthermore, living with a single parent, low level of

A. Milone, MD · F. Muratori, MD Scientific Institute 'Stella Maris' Pisa, Italy

P. Morosini, MD · G. Polidori, MD National Institute of Health Rome, Italy

F. Nardocci, MD - A. Tullini, MD Department of Mental Health Azienda ASL

Rimini, Italy 
maternal education, and low family income were associated with a higher likelihood of suffering from emotional or behavioral problems. Conclusions Approximately one in ten adolescents has psycholog- ical problems. Teachers and clinicians should focus on boys and girls living with a single parent and/or in disadvantaged socioeconomic conditions.

\section{Introduction}

Findings from the recent ESEMED-WMH Study suggest that the prevalence of mental disorders is lower in Italy compared to other European countries [15]. This prompted the need to clarify whether the same pattern can be observed in the developmental age. Indeed, while several studies have investigated the prevalence and correlates of mental disorders in childhood and adolescence in North-America and in Europe $[4,12,14,17$, $21,44,46]$, to date no epidemiological investigation of this type has been conducted in Italy.

The importance of early detection of mental disorders in preadolescence and adolescence is widely acknowledged, because these years are critical for the onset and development of later disturbances $[8,10$, $32,34]$. Therefore, accurate estimates of the prevalence of psychopathology for these age groups are essential for setting up adequate services, with the aim of diminishing the consequences of mental disorders on later development and functioning in adulthood. Moreover, valid and reliable screening and diagnostic measures based ideally on multiple informants can contribute to more precise prevalence estimates.

Individual and family characteristics may play a significant role in the onset of psychopathology in this developmental age [22]. In fact, although mental disorders are more common in boys than in girls during childhood and preadolescence-especially in terms of externalizing behaviors [12] - a trend in the opposite direction can be observed for adolescence, in that girls show high rates of internalizing behaviors [27]. Difficulties in school progression (defined by having repeated a grade) have been found to be more strongly associated with externalizing disorders than with internalizing disorders [6, 37, 45]. Moreover many studies have focused on the socioeconomic factor as a key correlate of psychopathology, but the relationship between socioeconomic level (defined in different ways as socioeconomic status, parental education level, and family income) and mental disorder is controversial. Most studies have found that children with low socioeconomic level are at increased risk of mental (especially behavioral) disorders, but other researchers have not reached the same conclusion [12, 27, 35]. Lastly, the variable of single-parent family has been found to be associated with externalizing disorders $[36,45]$.
The Italian preadolescent mental health project (PrISMA) [24] is a two-phase survey carried out in Italy to estimate the prevalence and correlates of mental health problems in urban preadolescents. The screening instrument is the child behavior checklist (CBCL) [2], a validated checklist filled out by parents, and the diagnostic instrument is the 'development and well-being assessment' (DAWBA) [29], a semistructured interview that combines information from parents and adolescents.

\section{Method}

The main features of the PrISMA study are summarized below. Full details concerning its research design and methods are available elsewhere [24].

\section{Sample}

The study population consisted of Italian preadolescents, aged 10-14 years, attending secondary school (6th-8th grade) and living in seven urban areas, including two metropolitan areas (the cities of Rome and Milan) and five small- to average-sized urban areas, which were selected according to willingness to participate in the study. Participant selection was conducted through schools, rather than by public register, due to the Italian personal data privacy law, which does not allow public registers to be viewed [26]. The PrISMA project was approved by the Italian Ministry of Health and by the ethics committee of each participating site. According to Italian law (DL 30 July 1999, $n .281$ and 282), informed consent was not required because the primary aim of the study was to assess the health status of the population.

Two-stage sampling was conducted separately at each site by randomly selecting a sample of schools and then by obtaining a random sample of individuals at each selected school. Secondary schools at each site were sampled with stratification by funding source (public/ private) and mean family income of adolescents attending each school (banded into high, medium and low). A minimum of four schools were selected for each stratum, to reflect the public/private ratio and the neighborhood affluence of the different urban areas. Figure 1 illustrates the subject flow in the two study phases. Of a total of 5,627 students potentially eligible for the screening phase, 
Fig. 1 Subject flowchart

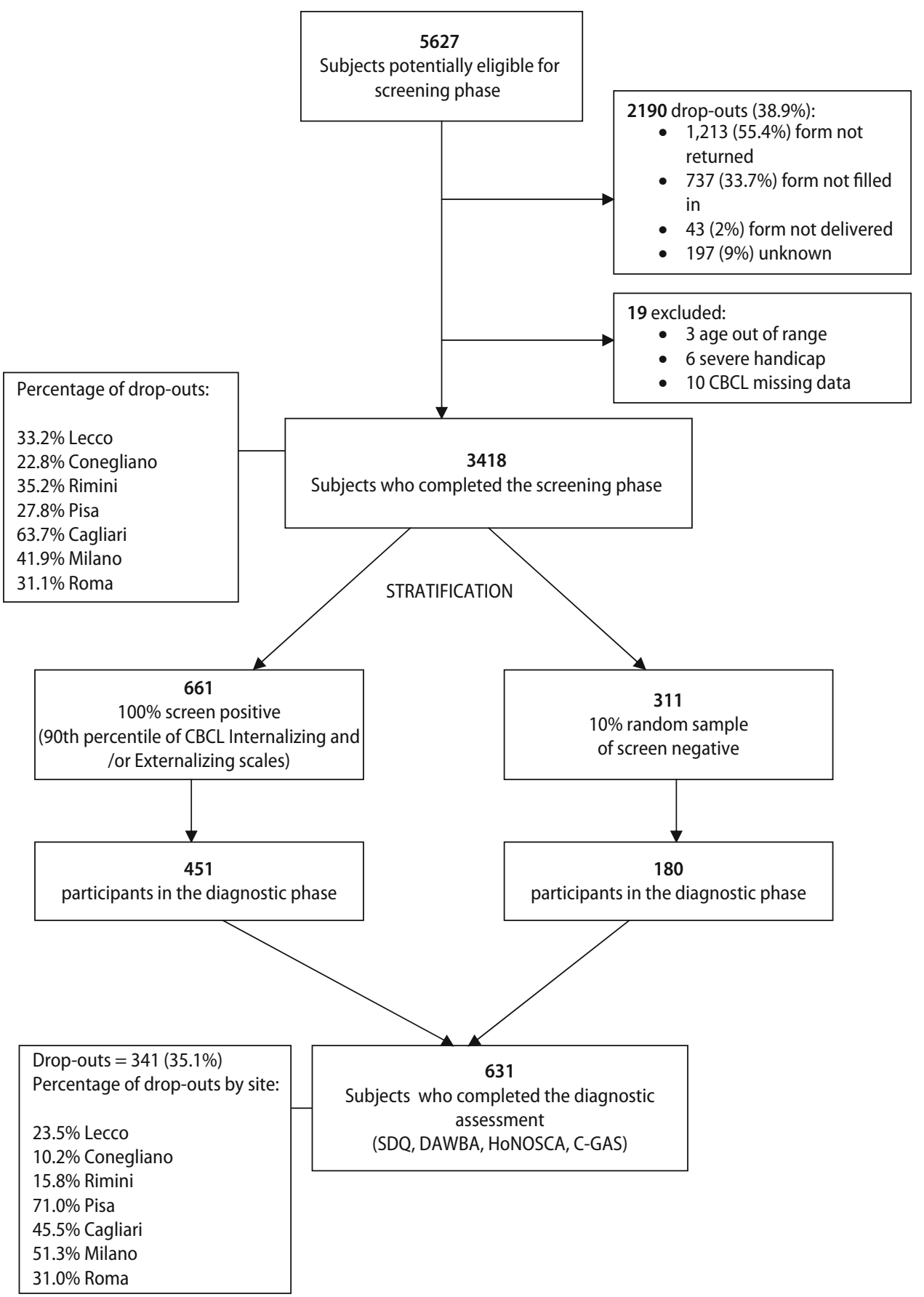

2,190 (38.9\%) did not participate. Non-participation rates varied by site $\left(\chi^{2}(6)=350.3, P<0.001\right)$, with increasing age $\left(\chi^{2}(3)=84.4, P<0.001\right)$, and were significantly higher in boys $\left(42 \%\right.$ vs. $36 \% ; \chi^{2}(1)=24.4$, $P<0.001)$. Three participants were subsequently excluded, because their age was out of the target range of adolescents who regularly attend secondary school (1014 years-old). Of the 3,434 who agreed to participate in Phase 1, six students were not eligible due to certification for severe handicap and a further ten participants were excluded from the analyses, due to missing data on the child behavior checklist/6-18 (CBCL).

The 3,418 participants in phase 1 were stratified according to whether they exceeded the 90th percentile of the internalizing and/or the externalizing scales of the CBCL. Phase 2 was conducted on all screen-positive participants and on a $10 \%$ random sample of screen-negative participants [24]. Of 661 
screen- positive and 311 screen-negative, 451 (68\%) and $180(57.8 \%)$ participated in phase 2 . Non-participation rate did not vary by age $\left(\chi^{2}(3)=1.98\right.$, $P=0.57)$ or gender $\left(\chi^{2}(1)=0.24, P=0.62\right)$, although it did vary by site $\left(\chi^{2}(6)=131.1, P=0.001\right)$.

\section{Instruments}

\section{The socio-demographic form}

The sample's individual and family characteristics were collected by using an ad hoc form filled out by parents. The form surveyed demographic data (adolescent gender and age, parents' marital status), variables related to the preadolescents' education and contact with services (school attended, repeated grades, presence of a remedial teacher, recourse to mental health services); variables related to the socioeconomic status of the family (educational level employment, and income of both parents). Socio-economic status (SES) was evaluated in terms of two indicators: parents' occupation and annual household income. Parental occupation was classified using the Hollingshead (1975) [31] 9-point scale for parental occupation. Income levels were defined according to criteria defined by Italian law regarding tax declaration [25].

\section{The child behavior checklist/6-18 (CBCL)}

The CBCL [2] is a questionnaire filled out by parents which is designed to assess social competence and behavioral problems in children and adolescents aged 6-18 years. The CBCL consists of two parts: the first part explores the social competences of children and adolescents and the second part investigates their behavioral and emotional problems. The CBCL includes 8 cross-informant syndrome scales (Anxious/Depressed, Withdrawn/Depressed, Somatic Complaints, Social Problems, Thought Problems, Attention Problems, Rule-Breaking Behavior and Aggressive Behavior), two broad-band scales (Internalizing and Externalizing), and a Total Problem scale. Validity and reliability studies have shown that the CBCL is an effective instrument for assessing emotional and behavioral problems in children [2]. The Italian version of the CBCL was obtained through independent back-translation authorized and approved by $\mathrm{T}$. Achenbach. Although no normative Italian data on the most recent CBCL are available to date, the psychometric properties of the previous CBCL version [1] have been investigated recently in a study conducted in Italy [23], which showed the good validity and reliability of the instrument for use on the Italian population.

Gender and age-specific thresholds on the Total Problem CBCL score were determined using Achenbach's normative data [2].

\section{Development and well being assessment: DAWBA}

Clinical assessment was conducted using the parent and adolescent versions of the DAWBA diagnostic interview [29], which combines a structured and a semi-structured part and is designed to generate present-state psychiatric diagnoses for children and adolescents following DSM - IV and ICD - 10 criteria. The structured sections explore the following psychopathological areas: separation anxiety, simple phobia, social phobia, panic disorder with/without agoraphobia, post-traumatic stress disorder (PTSD), obsessive-compulsive disorder, generalized anxiety disorder, major depression, attention deficit and hyperactivity disorder, behavioral disorder, and less common disorders. The semi-structured part of the interview elicits a verbatim account of any problems reported. The DAWBA has shown satisfactory validity and inter-rater reliability [21,29].

The interview was administered by trained interviewers (13 clinical psychologists and 12 child and adolescent psychiatry trainees), and diagnoses were made by five experienced clinical psychiatrists, who had been specifically trained in clinical DAWBA rating by the interview's author (RG). The raters reviewed preliminary computer-generated diagnoses by computer algorithm on the basis of symptom and impairment data, using information collected from parents, and then the verbatim transcripts in order to accept or modify the computer-generated diagnoses, and assign not-otherwise-specified (NOS) diagnoses. Hard-to-diagnose cases were jointly reviewed by raters, and all cases for which a clear consensus was not reached were then discussed further with RG. Interrater agreement was calculated from a random sample of 100 interviewed participants, rated separately by the interview team and by an independent Italian-speaking child psychiatrist (NM). The kappa coefficient of 0.71 was within the range as the coefficient yielded by the original English version of the interview [21]. To avoid small cell sizes and wide confidence intervals, diagnoses were grouped into "Any DSM-IV diagnosis", "Emotional disorders" (anxiety and depressive disorders), and "Externalizing disorders" (oppositional-defiant, conduct and attention-deficit/hyperactivity disorders) for the presentation of prevalence rates. Correlates and regression analyses are presented only for "Any DSM-IV diagnosis".

\section{Statistical analyses}

Unweighted data were used for Phase 1 data (CBCL), and weighted data were used for Phase 2 data. Binomial exact confidence intervals were calculated for Phase 1 prevalence estimates. Sampling weights were calculated to adjust DSM-IV prevalence estimates for 
response rate and the two-phase study design. Weights were obtained using logistic regression on first-phase participants, with response (yes/no) as the dependent variable and the CBCL internalizing and externalizing scores, gender, and area affluence (average, advantaged, disadvantaged) as the independent variables. Individual weight was calculated as the reciprocal of the resulting probability, so that participants with a lower response probability had a higher weight than participants with high response probability [16].

The association of demographic and social characteristics with (1) CBCL caseness and (2) presence of a DSM-IV diagnosis was examined using odds ratios (ORs) and logistic regression models. Variables significantly associated with caseness in univariate analyses at $P=0.05$ were entered into logistic regression models. Gender and the Gender $\times$ Age interaction were also entered into the models to test the study hypothesis that the increase in prevalence of psychopathology by age varies with gender. Due to the large number of participants with missing socioeconomic status (SES) and income data, these variables were analyzed in separate logistic regression models. All statistical analyses were conducted using STATA, release 8 [43], which includes a family of procedures for analyzing survey data.

\section{Results}

\section{Prevalence and correlates of psychopathology}

The prevalence of CBCL caseness and DSM-IV diagnosis was $9.8 \%$ (CI $8.8-10.8 \%$ ) and $8.2 \%$ (CI $4.2-$ $12.3 \%)$, respectively. DSM-IV emotional disorders were more frequent $(6.5 \%$ CI $2.2-10.8 \%)$ than externalizing disorders ( $1.2 \%$ CI $0.2-2.3 \%)$. Only three subjects met criteria for diagnoses not otherwise specified (NOS). Phase 1 and Phase 2 data were used to examine individual and family characteristics as potential correlates of psychopathology. Variables significantly associated with CBCL caseness in univariate analyses were: older age, having repeated a grade, living with a single parent, low-level of maternal and paternal education, low SES, and low income (Table 1). The same variables were significantly associated with DSM-IV disorders, with the exception of maternal education and SES, where the non-significance yielded may have been due to greater variability in the Phase 2 sample, given that the reduced ORs were larger for DSM-IV diagnoses than they were for CBCL caseness.

We further tested these associations using logistic regression models. In the first model (Table 2), male gender, having repeated a grade, having a single parent, and low level of maternal education remained significantly associated with CBCL caseness. The univariate analyses showed a similar pattern of association with DSM-IV diagnoses, although the only effect to reach statistical significance was living with a single parent (Table 2). We then examined the Gender $\times$ Age interaction. Figure 2 (panel A) shows that the prevalence of CBCL caseness increased with age in girls, with a peak at 14 years, but not in boys. Yet, confidence intervals were large and overlapped when data for boys and girls of the same age were compared. Prevalence of DSM-IV diagnoses (Fig. 2, panel B) showed the same trend, with a marked gender difference at age 14 .

Of the 336 adolescents with emotional and behavioral problems, $49(14 \%)$ had consulted a mental health service and $26(8 \%)$ had a remedial teacher.

Adolescents with CBCL-assessed emotional and behavioral problems were approximately five times more likely to have a remedial teacher $(\mathrm{OR}=4.99$; $\mathrm{CI}=3.07-8.13)$ and to have consulted mental health services $(\mathrm{OR}=5.23 ; \mathrm{CI}=3.67-7.63)$ than adolescents presenting no such problems. Similarly, adolescents with a DAWBA-diagnosed mental disorder were approximately nine times more likely to have a remedial teacher $(\mathrm{OR}=9.48 ; \mathrm{CI}=6.23-14.43)$ and to have consulted mental health services $(\mathrm{OR}=8.87$; $\mathrm{CI}=6.18-12.72)$ than adolescents with no disorder.

\section{Discussion}

To our knowledge, the PrISMA study is the first epidemiological survey on mental disorders in a large sample of Italian adolescents that has used standardized diagnostic and screening instruments.

\section{Prevalence of mental disorders in adolescents}

The screening and diagnostic instruments we used to estimate the prevalence of psychopathology in Italian adolescents yielded similar rates (9.8 and 8.2\%).

The overall prevalence of mental disorders in Italian adolescents $(8.2 \%)$ was similar to that found in other studies conducted in European countries [e.g. 21]. However, in contrast with findings from other studies $[3,12,14,19,21,44,46]$ that reported prevalence estimates of externalizing disorders of 4$7 \%$, the percentage of Italian adolescents with these disorders was only $1.2 \%$. These data are consistent with findings on Italian adults $[15,18,28]$. In particular, the recent ESEMeD-WMH study [15] indicates that compared to other European countries and 


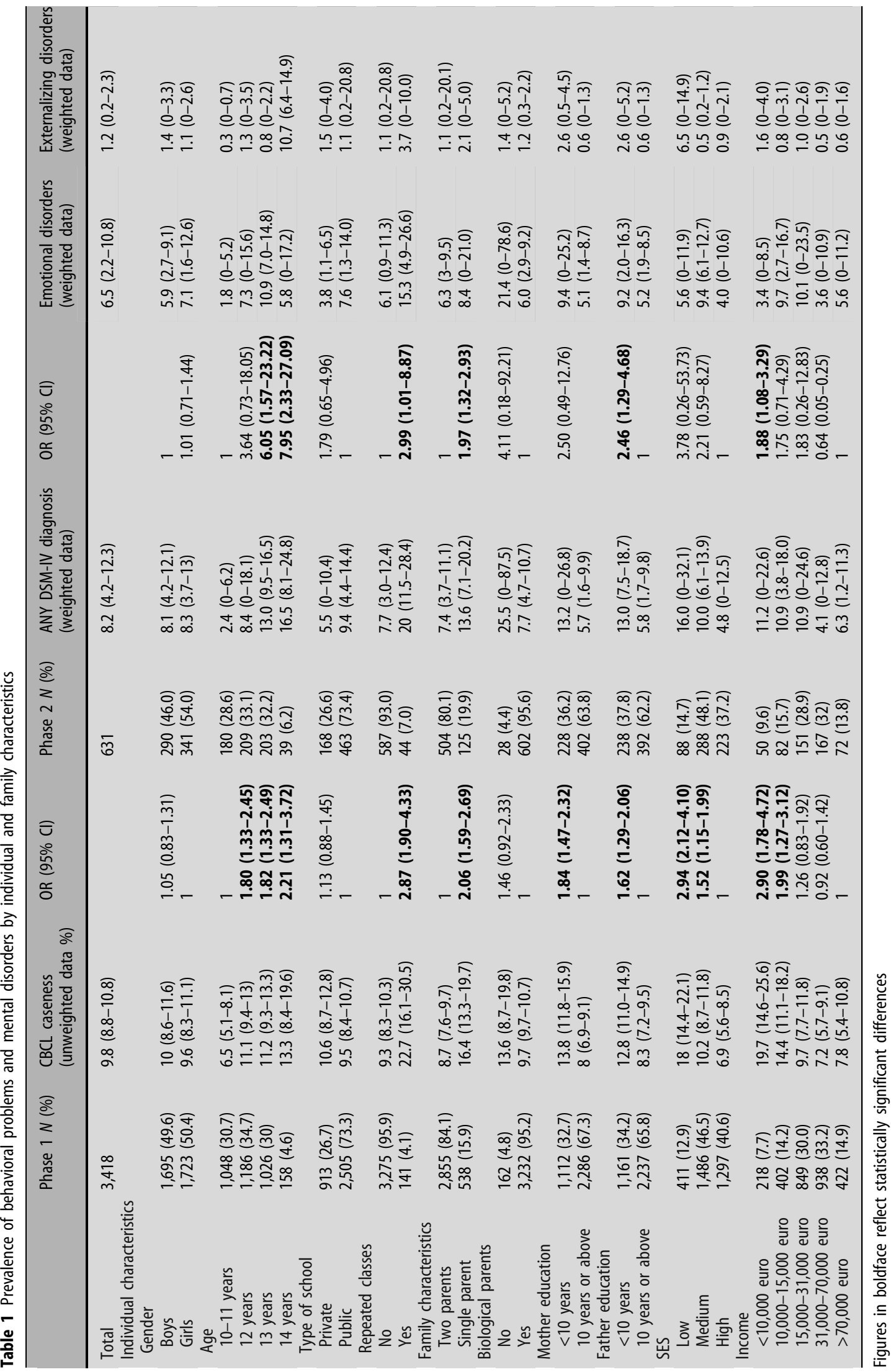


Table 2 Correlates of CBCL and DSM-IV caseness

\begin{tabular}{|c|c|c|c|c|c|c|}
\hline & \multicolumn{3}{|c|}{ Phase 1 (CBCL) } & \multicolumn{3}{|c|}{ Phase 2 (DAWBA) } \\
\hline & \multirow[t]{2}{*}{ OR } & \multicolumn{2}{|c|}{$95.0 \% \mathrm{Cl}$} & \multirow[t]{2}{*}{ OR } & \multicolumn{2}{|c|}{$95.0 \% \mathrm{Cl}$} \\
\hline & & Lower & Upper & & Lower & Upper \\
\hline \multicolumn{7}{|l|}{ Individual characteristics } \\
\hline \multicolumn{7}{|l|}{ Age } \\
\hline $10-11$ years & 1 & & & 1 & & \\
\hline 12 years & 1.16 & 0.77 & 1.76 & 2.90 & 0.85 & 9.89 \\
\hline 13 years & 1.30 & 0.85 & 1.97 & 3.15 & 0.48 & 20.65 \\
\hline 14 years & 0.53 & 0.22 & 1.24 & 0.83 & 0.06 & 11.60 \\
\hline \multicolumn{7}{|l|}{ Gender } \\
\hline$M$ & 1 & & & 1 & & \\
\hline $\mathrm{F}$ & 0.54 & 0.32 & 0.90 & 0.59 & 0.24 & 1.45 \\
\hline \multicolumn{7}{|l|}{ Gender $\times$ Age } \\
\hline 12 years - girls & 2.20 & 1.17 & 4.16 & 0.99 & 0.44 & 2.21 \\
\hline 13 years - girls & 1.71 & 0.89 & 3.27 & 2.51 & 0.20 & 31.50 \\
\hline 14 years - girls & 7.34 & 2.41 & 22.36 & 26.47 & 0.68 & 1026.15 \\
\hline \multicolumn{7}{|l|}{ Repeated class } \\
\hline No & 1 & & & 1 & & \\
\hline Yes & 2.42 & 1.52 & 3.85 & 2.09 & 0.37 & 11.68 \\
\hline \multicolumn{7}{|l|}{ Family characteristics } \\
\hline \multicolumn{7}{|l|}{ Marital status } \\
\hline Two parents & 1 & & & 1 & & \\
\hline Single parent & 2.03 & 1.55 & 2.66 & 1.86 & 1.16 & 2.98 \\
\hline \multicolumn{7}{|l|}{ Mother education } \\
\hline$<10$ years & 1.59 & 1.21 & 2.08 & 1.89 & 0.34 & 10.39 \\
\hline$>10$ years or above & 1 & & & 1 & & \\
\hline \multicolumn{7}{|l|}{ Father education } \\
\hline$<10$ years & 1.24 & 0.94 & 1.63 & 1.71 & 0.87 & 3.38 \\
\hline$>10$ years or above & 1 & & & 1 & & \\
\hline
\end{tabular}

Figures in boldface reflect statistically significant differences. Results from logistic regression

the US, in Italy the prevalence rates of anxiety $(5.8 \%$ CI $4.5-7.1 \%)$ and mood disorders (3.8\% CI 3.1$4.5 \%)$ are lower and those of impulse control $(0.3 \%$ 95\% CI $0.1-0.5)$ and substance use (0.1\% 95\% CI 00.2 ) disorders are the lowest. Although externalizing disorders in childhood and adolescence do not completely overlap with adulthood disorders, it is remarkable that low rates of externalizing disorders were found in Italy despite differences in age range and diagnostic measures. If, as is likely, this pattern reflects cultural rather than genetic variables or methodological factors related to the study, then further investigation into a possible explanation for the low externalizing rates observed in Italians would be of considerable interest to both policy makers and clinicians.

\section{Correlates of mental disorders in adolescents}

The correlates of psychopathology did not differ by instrument (CBCL or DAWBA) in univariate analyses. Conversely, the different results yielded by multivariate analyses are an effect of the smaller Phase 2 sample size.
The demographic and social correlates of psychopathology identified in the present study are generally consistent with those reported in other epidemiological studies [e.g. 7, 19, 21]. Prevalence rates for girls increased with age, in line with results from several studies $[3,11,14]$ reporting an increase in the prevalence of mental disorders- especially internalizing disorders- in girls at the onset of puberty. Our sample did not show a corresponding increase with age in boys, in all likelihood because of the low prevalence of externalizing disorders observed for this group. However, the small number of 14-years-old subjects recruited from the 8th grade and the higher attrition rate at this age suggests caution in the interpretation of findings. Yet, boys in our study did show a higher risk of psychopathology than girls-a finding reported by other studies employing similar screening and/or diagnostic tools [12, 20, 21, 23, 44].

The presence of psychological problems and fullblown mental disorders was associated with school problems, such as having repeated a grade and having a remedial teacher. Although school problems might represent a consequence of psychological problems, our cross-sectional study cannot demonstrate a causeeffect relationship. In fact, we cannot rule out the 

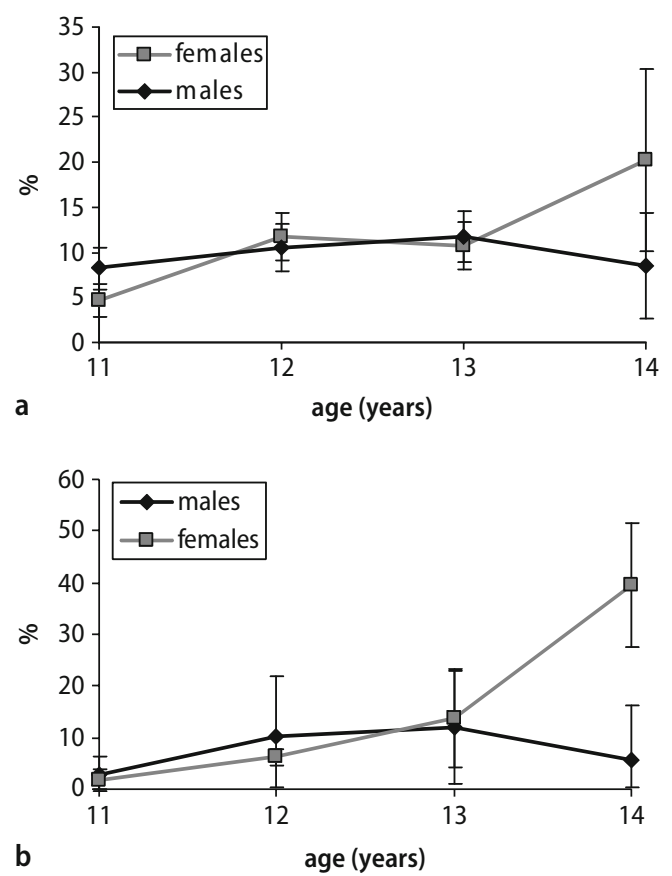

Fig. 2 Prevalence of $C B C L$ (panel A) and DSM-IV disorders (panel B) by age and gender. Error bars denote: $95 \%$ confidence intervals

possibility that negative school experiences may act as stressors in adolescents' lives and trigger psychological problems.

Our finding of an association between mental disorder and recourse to mental health services can be seen as a welcome sign that referral patterns to these services are qualitatively appropriate. At the same time, however, the fact that over $80 \%$ of participants with significant mental health problems had not yet consulted mental health services suggests that referral is quantitatively inadequate. This latter finding is consistent with other studies reporting a large gap between mental health service use and need for services, both in American and in European countries [3, $13,39,42]$. Furthermore, our findings mirror the results from the ESEMeD-WMH study showing that Italian adults with mental disorders had the lowest probability of receiving adequate treatment of all European countries investigated [15]. Further studies should therefore focus on factors associated with both mental health service needs (and unmet needs) and effective utilization, in order to better understand why a large proportion of Italian youths and adults do not seek professional help.

Of the family characteristics investigated, living with a single parent was a strong correlate of psychopathology in line with other studies [7,9]. Furthermore, low parental education (less than 10 years) was associated with a higher likelihood of CBCL caseness and DSM-IV disorders. Secondary analyses indicated that the father's education was positively correlated with socioeconomic level (Spearman $\rho=0.43, P<0.01)$ and annual household income (Spearman $\rho=0.4, P<0.01$ ), which were both also associated with psychopathology in the univariate analyses. Therefore, even though all three variables could not be included in a single model - due to missing data on income and socio-economic level data-it is quite likely that the co-occurrence of poor social conditions and low income increase prevalence rates. Further studies are required to better define the complex interplay of psychopathology in adolescence with individual and family correlates.

\section{Limitations}

The results of the PrISMA study should be interpreted in the context of several study limitations. First, it might be argued that participants are not representative of Italian adolescents aged 10-14 because they were recruited from schools and not from public registers. However, because the school attendance rate in Italy is mandatory for the age group examined and is approximately 96\% (Annuario Statistico Italiano 2005, Istat), adolescents attending schools can be considered representative of the population of boys and girls of the same age. Second, the study is not representative of Italian adolescents living in nonurban areas. Although it is likely that geographical area is not a factor that is associated per se with mental disorders, our investigation does not allow one to draw reliable inferences about the mental health conditions of Italian adolescents living in rural areas. Nor does it contribute to a final understanding of the role played by neighborhood socioeconomic status as an important factor in the frequently observed association between geographical area and mental disorders [12, 38]. Third, non-participation rates differed by gender, age, and site in Phase 1, and by site in Phase 2. Furthermore, the response rate in the two phases was 61 and $65 \%$. In the light of these limitations, it is likely that adolescents who did not take part in the study, especially boys, may have had higher rates of emotional and behavioral disorders and may also have differed from our participants in terms of exposure to risk factors [33]. As a consequence, our results might be biased by the underrepresentation of more severe cases and of older adolescents (aged 14 years). Regarding site, the high attrition rate at Cagliari was consistent between the two phases, while at Pisa participation was high in phase I and dropped in phase II as a result of a campaign aimed to demonize this study, in anticipation of a potential 'early psychiatrization' of adolescents. The impact of the high attrition rate at these 
two sites in phase II is the increased variability in the prevalence estimates and the limited generalizability of the overall results to adolescents living at Cagliari and Pisa.

Fourth, the small number of subjects meeting criteria for a diagnosis precluded analysis at the level of individual diagnoses. However, despite the lack of a focus on specific diagnoses representing a limitation of the study, the classification of mental disorders into Externalizing and Internalizing groups is widely employed and well-validated, and can also contribute to explaining the comorbidity among individual mental disorders [40, 41]. Last, the age and stage of puberty were not assessed. This type of information could have contributed to elucidate the reasons for the increase in prevalence of mental problems in girls with age, thus providing additional empirical evidence on the role played by puberty in the onset of mental disorders.

\section{Clinical implications}

With a prevalence rate of mental disorders of approximately $8 \%$ in Italian adolescents, increased focus on prevention and early recognition of adolescents in need of treatment is crucial. Furthermore, similarly to findings observed in other cultures [for a review see 13], a large proportion of Italian youths who need intervention do not seek professional help, increasing the risk of persistent mental disorders and a heavy impact on their adult-age functioning thereby. Lastly, living with a single parent was found to be one of the strongest correlates of psychopathology. Therefore, teachers need to be made aware that adolescents living in single parent households have a higher vulnerability to mental disorders.

\section{Conclusion}

Although overall prevalence rates yielded by the PrISMA study are comparable to those found in other recent investigations, a lower proportion of Italian adolescents presented externalizing disorders than participants surveyed in American and in European studies. Moreover, other studies using the DAWBA diagnostic interview in approximately the same age range have also reported a higher prevalence of externalizing disorders than that found in our study $[19,21,30]$. Lastly, the findings of the ESEMeD-WMH study showing Italian adults with the lowest prevalence rates of externalizing disorders, as compared with adults from other European and American countries generate intriguing questions about the influence of cultural variables on psychopathology [5]. It can be speculated that some peculiar characteristics of Italian families (tendency to be resident in the same native place, maintaining sons/daughters well into young adulthood) may act as protective factors in preventing the onset of externalizing disorders.

Further epidemiological studies based on large samples are needed to test these hypotheses.

\section{References}

1. Achenbach TM (1991) Manual for the child behavior checklist/4-18 and 1991 profiles. University of Vermont, Department of Psychiatry, Burlington

2. Achenbach TM, Rescorla LA (2001) Manual for the ASEBA School-age forms and profiles. University of Vermont, Department of Psychiatry, Burlington

3. Angold A, Erkanli A, Farmer EMZ, Fairbank JA, Burns BJ, Keeler G, Costello EJ (2002) Psychiatric disorder, impairment, an service use in rural African American and white youth. Arch Gen Psychiatry 59:893-901

4. Bilenberg N, Petersen DJ, Hoerder K, Gillberg C (2005) The prevalence of child-psychiatric disorders among 8-9year-old children in Danish mainstream schools. Acta Psychiatr Scand 111:59-67
5. Bird HR (1996) Epidemiology of childhood disorders in a cross-cultural context. J Child Psychol Psychiatry 37:35-49

6. Bird HR, Gould MS, Yager T, Staghezza B, Canino G (1989) Risk factors for maladjustment in Puerto Rican children. J Am Acad Child Adolesc Psychiatry 28:847-850

7. Boys A, Farrell M, Taylor C, Marsden J, Goodman R, Brugha T, Bebbington P, Jenkins R, Meltzer H (2003) Psychiatric morbidity and substance use in young people aged 13-15 years: results from the child and adolescent survey of mental health. Br J Psychiatry 182:509517

8. Burke KC, Burke JD, Regier DA, Rae DS (1990) Age at onset of selected mental disorders in five community populations. Arch Gen Psychiatry 47:511-518
9. Canino G, Shrout PE, Rubio-Stipec M, Bird HR, Bravo M, Ramirez R, Chavez L, Alegria M, Bauermeister JJ, Hohmann A, Ribera J, Garcia P, MartinezTaboas A (2004) The DSM-IV rates of child and adolescent disorders in Puerto Rico. Arch Gen Psychiatry 61:85-93

10. Christie KA, Burke JD, Gruenberg E et al (1988) Epidemiologic evidence for early onset of mental disorders: prevalence findings from recent studies. J Am Acad Child Adolesc Psychiatry 29:76-85

11. Cohen P, Cohen J, Kasen S, Velez CN, Hartmark C, Johnson J, Rojas M, Brook J, Streuning EL (1993) An epidemiological study of disorders in late childhood and adolescence-I. age and gender-specific prevalence. J Child Psychol Psychiatry 34:851-867 
12. Costello EJ, Angold A, Burns BJ, Stangl DK, Tweed DL, Erkanli A, Worthman CM (1996) The great smoky mountains study of youth. goals, design, methods, and the prevalence of DSM-III-R disorders. Arch Gen Psychiatry 53:11291136

13. Costello EJ, Egger H, Angold A (2005) 10 -year research update review: the epidemiology of child and adolescent psychiatric disorders: I. Methods and public health burden. J Am Acad Child Adolesc Psychiatry 44:972-986

14. Costello EJ, Mustillo S, Erkanli A, Keeler G, Angold A (2003) Prevalence and development of psychiatric disorders in childhood and adolescence. Arch Gen Psychiatry 60:837-844

15. Demyttenaere K, Bruffaerts R, PosadaVilla J, Gasquet I, Kovess V, Lepine JP, Angermeyer MC, Bernert S, de Girolamo G, Morosini P, Polidori G, Kikkawa T, Kawakami N, Ono Y, Takeshima T, Uda H, Karam AN, Mneimneh ZN, Medina-Mora ME, Borges G, Lara C, de Graaf R, Ormel J, Gureje O, Shen Y, Huang Y, Zhang M, Alonso J, Haro JM, Vilagut G, Bromet EJ, Gluzman S, Webb C, Kessler RC, Merikangas KR, Anthony JC, Von Korff MR, Wang PS, Brugha TS, Aguilar-Gaxiola S, Lee S, Heeringa S, Pennell BE, Zaslavsky AM, Ustun TB, Chatterji S. WHO Mental Health Survey Consortium (2004) Prevalence, severity, and unmet need for treatment of mental disorders in the World Health Organization world mental health surveys. JAMA 291:25812590

16. Dunn G, Pickles A, Tansella M, Vazquez-Barquero JL (1999) Two phase epidemiological surveys in psychiatric research. Br J Psychiatry 174:95-100

17. Ezpeleta L, Guillamon N, Granero R, de la Osa N, Domènech JM, Moya I (2007) Prevalence of mental disorders in children and adolescents from a Spanish slum. Soc Sci Med 64:842-849

18. Faravelli C, Abrardi L, Bartolozzi D, Cecchi C, Cosci F, D'Adamo D, Lo Iacono B, Ravaldi C, Scarpato MA, Truglia E, Rossi Prodi PM, Rosi S (2004) The Sesto Fiorentino study: point and one-year prevalences of psychiatric disorders in an Italian community sample using clinical interviewers. Psychother Psychosom $73: 226-234$

19. Fleitlich-Bilyk B, Goodman R (2004) Prevalence of child and adolescent psychiatric disorders in southeast Brazil. J Am Acad Child Adolesc Psychiatry 43:727-734

20. Fombonne E (1995) The chartres study: I. Prevalence of psychiatric disorders among French school-aged children. Br J Psychiatry 164:69-79
21. Ford T, Goodman R, Meltzer H (2003) The British child and adolescent mental health survey 1999: the prevalence of DSM IV disorders. J Am Acad Child Adolesc Psychiatry 42:1203-1211

22. Ford T, Goodman R, Meltzer H (2004) The relative importance of child, family, school and neighbourhood correlates of childhood psychiatric disorder. Soc Psychiatry Psychiatr Epidemiol 39:487-496

23. Frigerio A, Cattaneo C, Cataldo MG, Schiatti A, Molteni M, Battaglia M (2004) Behavioral and emotional problems among Italian children Aged 4-18 years as reported by parents and teachers. Eur J Psychol Assess 20:124133

24. Frigerio A, Vanzin L, Pastore V, Nobile M, Giorda R, Marino C, Molteni M, Rucci P, Ammaniti M, Lucarelli L, Lenti C, Walder M, Martinuzzi A, Carlet O, Muratori F, Milone A, Zuddas A, Cavolina P, Nardocci F, Rullini A, Morosini P, Polidori G, De Girolamo G (2006) The Italian preadolescent mental health project (PrISMA): rationale and methods. Int J Methods Psychiatr Res 15:2235

25. Gazzetta Ufficiale, Serie Generale, Numero 302, Capo Secondo, Articolo 2, Rome: Istituto Poligrafico e Zecca dello Stato, 2001

26. GazzettaUfficiale. (Legge $675 \mathrm{del}$ 31.12.1996). "Tutela delle persone e di altri soggetti rispetto al trattamento dei dati personali" [The protection of people and other individuals in the relationship to management of personal data]

27. Gelder MG, Lopez-Ibor JJ, Andreasen N (2000) New Oxford textbook of psychiatry. Oxford University Press, Oxford

28. Gigantesco A, Palumbo G, Mirabella F, Pettinelli M, Morosini P (2006) Prevalence of psychiatric disorders in an Italian town: low prevalence confirmed with two different interviews. Psychother Psychosom 75:170-176

29. Goodman R, Ford T, Richards H, Gatward R, Meltzer H (2000) The development and well-being assessment: description and initial validation of an integrated assessment of child and adolescent psychopathology. J Child Psychol Psychiatry 41:645-655

30. Goodman R, Slobodskaya H, Knyazev G (2005) Russian child mental health. A cross-sectional study of prevalence and risk factors. Eur Child Adolesc Psychiatry $14: 28-33$

31. Hollingshead AB (1975) Four factor index of social status. Unpublished manuscript. Yale University, Department of Sociology, New Haven
32. Kessler RC, Berglund P, Demler O, Jin R, Merikangas KR, Walters EE (2005) Lifetime prevalence and age-of-onset distributions of DSM-IV disorders in the national comorbidity survey replication. Arch Gen Psychiatry 62:593-602

33. Kessler RC, Little RJA, Groves RM (1995) Advances in strategies for minimizing and adjusting for survey non response. Epidemiol Rev 17:192-204

34. Lewinsohn PM, Duncan EM, Stanton AK, Hautzinger M (1986) Age at first onset for nonbipolar depression. J Abnorm Psychol 4:378-383

35. Meltzer H, Gatward R, Goodman R, Ford T (2000) Mental health of children and adolescents in Great Britain. The Stationery Office, London

36. Munroe-Blum H, Boyle M, Offord DR (1988) Single parent families: child psychiatric disorder and school performance. J Am Acad Child Adolesc Psychiatry 27:214-219

37. Offord DR, Boyle MH, Racine Y (1989) Ontario child health study: correlates of disorder. J Am Acad Child Adolesc Psychiatry 28:856-860

38. Rutter M (1981) The city and the child. Am J Orthopsychiatry 51:610-625

39. Saunders S, Resnick M, Hoberman H, Blum RW (1994) Formal help-seeking behavior of adolescents identifying themselves as having mental health problems. J Am Acad Child Adolesc Psychiatry 33:718-728

40. Slade T (2007) The descriptive epidemiology of internalizing and externalizing psychiatric dimensions. Soc Psychiatry Psychiatr Epidemiol 42:554560

41. Slade T, Watson D (2006) The structure of common DSM IV and ICD 10 mental disorders in the Australian general population. Psychol Med 36:1593-1600

42. Sourander A, Helstela L, Ristkary T, Ikaheimo K, Helenius H, Piha J (2001) Child and adolescent mental health service use in Finland. Soc Psychiatry Psychiatr Epidemiol 36:294-298

43. Stata Corporation (2003) Stata statistical software: release 8.0. Stata Corporation, College Station

44. Steinhausen HC (2006) Developmental psychopathology in adolescence: findings from a Swiss study-the NAPE lecture 2005. Acta Psychiatr Scand 113:6-12

45. Velez CN, Johnson J, Cohen P (1989) A longitudinal analysis of selected risk factors for childhood psychopathology. J Am Acad Child Adolesc Psychiatry 28:861-864

46. Verhulst FC, van der Ende J, Ferdinand RF, Kasius MC (1997) The prevalence of DSM-III-R diagnoses in a national sample of Dutch adolescents. Arch Gen Psychiatry 54:329-336 